\title{
Impacts of snow conditions on tourism demand in Austrian ski areas
}

\author{
Christoph Töglhofer ${ }^{1,2, *}$, Franz Eigner ${ }^{1}$, Franz Prettenthaler ${ }^{1,2}$ \\ ${ }^{1}$ Wegener Center for Climate and Global Change, University of Graz, Leechgasse 25, 8010 Graz, Austria \\ ${ }^{2}$ Joanneum Research, Centre for Economic and Innovation Research, Elisabethstraße 20/II, 8010 Graz, Austria
}

\begin{abstract}
Major research efforts have been devoted to studying the impacts of climate change on snow conditions in ski areas, including snow making as a technical adaptation strategy in recent years. However, little attention has been paid to quantifying past demand changes owing to shortterm climate variability. This paper examines the impacts of snow conditions on tourism demand in 185 Austrian ski areas in the period 1972/1973 to 2006/2007. For the majority of areas, a positive relationship is found between overnight stays and snow conditions; however, overnight stays in higherlying areas typically show no dependency on snow conditions. Instead, some of them negatively depend on average Austrian snow conditions. Overall, a 1 standard deviation change in snow conditions led to a change in overnight stays of 0.6 to $1.9 \%$, with estimates from the most reliable panel data models of 0.6 and $1.1 \%$. Impacts were significantly higher for particular regions and for extreme seasons. However, temporal analysis reveals that impacts have decreased in recent years, probably owing to the major increase in snowmaking.
\end{abstract}

KEY WORDS: Climate variability $\cdot$ Tourism $\cdot$ Snow $\cdot$ Regression analysis $\cdot$ Panel data $\cdot$ Austria

\section{INTRODUCTION}

Tourism plays a fundamental role in the Austrian economy. In 2005, 21.6 billion Euros in direct and indirect value added [ $8.8 \%$ of the gross domestic product (GDP)] resulted from tourism activity. There were more than 30 million arrivals and 120 million overnight stays (Laimer \& Smeral 2006). A large share of tourism activity takes place in the 345 municipalities with major ski areas. These account for 44 million of the 60 million overnight stays in the winter season. Owing to the importance of the ski tourism industry, researchers and the public have become particularly concerned about the consequences of climate change.

Numerous studies have focused on understanding the past and possible future changes in winter temperature and precipitation patterns on the length of ski seasons and snow reliability, not only in Austria but also in other countries with a substantial skiing industry (Switzerland, France, Italy, USA, Canada, etc.). Several studies have been conducted covering natural snow conditions (Harrison et al. 1986, Lamothe \& Périard Consultants 1988, Galloway 1988, Lipski \& McBoyle 1991, McBoyle \& Wall 1992, König \& Abegg 1997, Breiling \& Charamza 1999, Elsasser \& Bürki 2002, Fukushima et al. 2002, Abegg et al. 2007). More recently, studies have also begun to examine the impact of climate change on the future importance of artificial snowmaking (Scott et al. 2003, 2006, Teich et al. 2007, Hennessy et al. 2008, Scott et al. 2008, Steiger \& Mayer 2008). These studies (supply-side studies) have thoroughly described changes in climatic conditions and their overwhelmingly negative effects in ski areas.

However, comparatively little effort has been made to systematically quantify the relationship between past weather conditions and the economic performance of ski areas (demand-side studies). In other words, although climate change is recognized as being an important factor in alpine tourism, the impact of climate variability on tourism demand over recent decades has largely been neglected in studies, with 3 
recent exceptions. Dawson et al. (2009) used an analogue approach for examining the impact of anomalously warm winters on total skier visits and operating profits in the northeast region of the US. They compared the economic performance of the ski industry in climatically normal winters and in winters which can be regarded as representative of future average climate conditions under different greenhouse gas emissions scenarios. Hamilton et al. (2007) chose an ARMAX time series model to examine daily variations in visitor numbers for 2 New England ski areas. They covered snow conditions both in the respective areas and in the city of Boston to check for the influence of urban snow conditions ('backyard hypothesis'). Similarly, Shih et al. (2009) used multiple linear regression models to analyze the weather dependency of ski lift ticket sales at 2 Michigan ski resorts. All of these studies found a clear relationship between snow or temperature conditions and the economic indicators examined.

Other, lesss specific studies have been conducted on a wider spatial and temporal scale to determine the more general relationship between weather and tourism demand. Agnew \& Palutikof (2006) applied time series regression models to look into the impacts of temperature, precipitation and sunshine in the UK on the demand for international and domestic tourism. Bigano et al. (2005) used a similar approach for tourism demand in Italian regions, and expanded the regression models by using panel estimations. Although the results were relatively weak for the UK, temperature was found to correlate positively with Italian tourism demand in summer, and negatively with tourism demand in alpine regions in winter. The authors suggested that the latter effect may be due to the negative influence of high temperatures on the skiing season. A series of other studies (Maddison 2001, Lise \& Tol 2002, Hamilton et al. 2005, Bigano et al. 2006) used crosssectional data to determine the optimal temperature for international tourism, but did not specifically incorporate the temperature requirements of alpine winter tourism into their models.

The present study goes beyond other demand-side studies in that it considers the link between snow conditions and tourism demand both on a local scale and for a relatively large number of cases (185 ski areas). When focusing on weather impacts in alpine regions, working on a local scale is essential, as this makes it possible to incorporate the complex microclimatic conditions across regions. Furthermore, using a large number of cases allows for comparison of sensitivities between different regions. In addition, the utilization of data for 34 winter seasons means that changes in snow sensitivity over time can be observed and that time series characteristics of demand data can also be taken into account.

\section{DATA AND METHODOLOGY}

In this section, we present an approach for determining the sensitivity of tourism demand in Austrian ski areas to seasonal snow conditions. Tourism demand is expected to depend, among other 'unknown' factors, on the meteorological conditions in the ski areas, the supply of tourism infrastructure and the economic conditions prevailing in the guests' countries of origin. We start the analysis by discussing the nature of the data and the expected influence of the variables on local tourism demand. The formal econometric model specifications are then presented.

\subsection{Data preparation}

As a first step, economic and meteorological data were collected for the major Austrian ski areas. This was particularly challenging because statistical tourism data provided by Statistics Austria (2008) is given on a municipal level whereas meteorological data are given either for selected measurement stations or on a grid basis. Hence, municipalities with skiing activities were matched to ski areas, and the altitude, size and exact location of the ski areas were determined, based on several data sources (Joanneum Research 2008, bergfex 2009, BEV 2009). The altitudes and coordinates of the ski areas were then provided for the meteorological model and snow indices were calculated. Altogether, 345 municipalities were assigned to 202 ski areas; the respective areas met the chosen size constraint of more than 5 transport facilities or at least 1 cable car in the area. Because lack of data meant that 17 areas (mostly small) had to be excluded, model calculations were carried out for the remaining 185 ski areas.

\subsection{Tourism demand data}

In general, data on ski lift ticket sales should be more responsive to changes in weather conditions than tourism indicators such as overnight stays or arrivals. These data include sales from day trippers, who are particularly flexible and sensitive to adverse weather conditions. By contrast, overnight stays or arrivals might be relatively less responsive, because terms of cancellation might encourage people to set out on a journey even when the weather forecast is unfavourable. Once the tourists have arrived in ski areas, they have the opportunity to replace skiing with some other activity during periods of bad weather conditions, especially in medium to high price destinations. The problem is, however, that consistent data on ski lift ticket sales are only available for a limited number of ski areas. Hence, unlike other re- 
cent studies relying on case study data on ski area visitors (Hamilton et al. 2007, Shih et al. 2009), we based our analysis on overnight stays in ski areas.

Figs. 1 and 2 show the Austrian municipalities categorized according to the mean altitudes of ski areas and the development of overnight stays in the winter seasons from 1972/1973 to 2006/2007 for the respective altitude categories. Overall, the number of overnight stays has grown in 27 out of 34 seasons, with the most notable exceptions occurring in the mid-1990s. However, looking at the different altitude categories reveals that, in the last $20 \mathrm{yr}$, considerable growth can only be observed in municipalities with ski areas above $1800 \mathrm{~m}$ and in non-skiing municipalities. By contrast, declining trends predominate in lower-lying municipalities $(<1200 \mathrm{~m})$, typically those of a smaller area.

\subsection{Meteorological data}

Consistent snow measurements for longer time series, as needed for our analysis, could only be found for a limited number of measurement stations and would not have covered regional snow variations and respective altitude of ski areas. Thus, we chose to take data from a snow cover model, which uses air temperature and precipitation data to reconstruct historic snow conditions for each of the given ski area coordinates, both for the lowest and mean altitudes. The data were provided by the Central Institute for Meteorology and Geodynamics (ZAMG 2009) and are available on a $1 \times 1 \mathrm{~km}$ grid for the period 1973 to 2006. Of course, although this procedure creates a more consistent data set, the underlying uncertainties regarding the extensive assumptions behind the snow model (e.g. spatial interpolation of data, assumptions about accumulation and ablation of snow cover) also need to be taken into account. For a more detailed discussion of the model, see Beck et al. (2009).

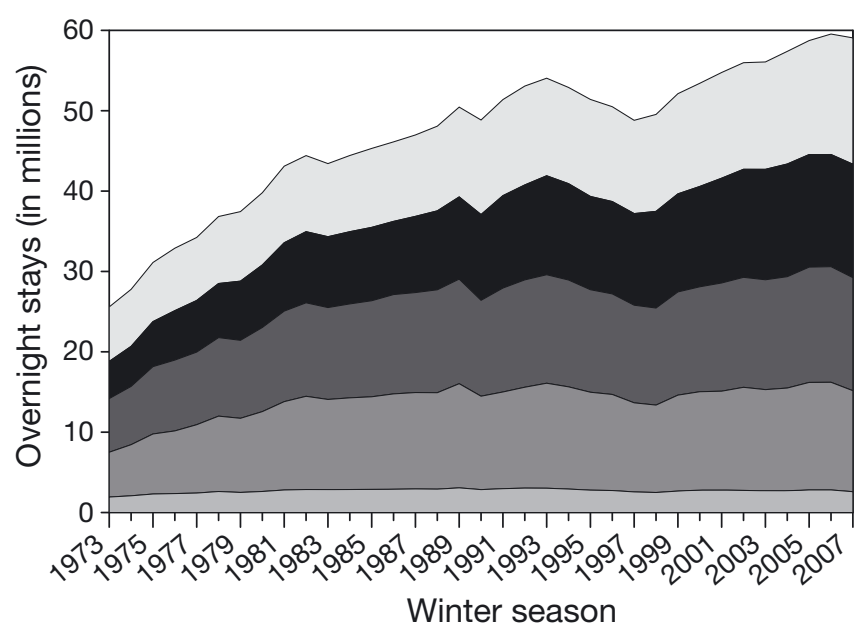

Fig. 2. Development of overnight stays in the winter seasons $1972 / 1973$ to $2006 / 2007$ dependent on the mean altitude of the ski areas in the respective municipalities. See Fig. 1 legend for altitude categories. Data source: Statistics Austria (2008)

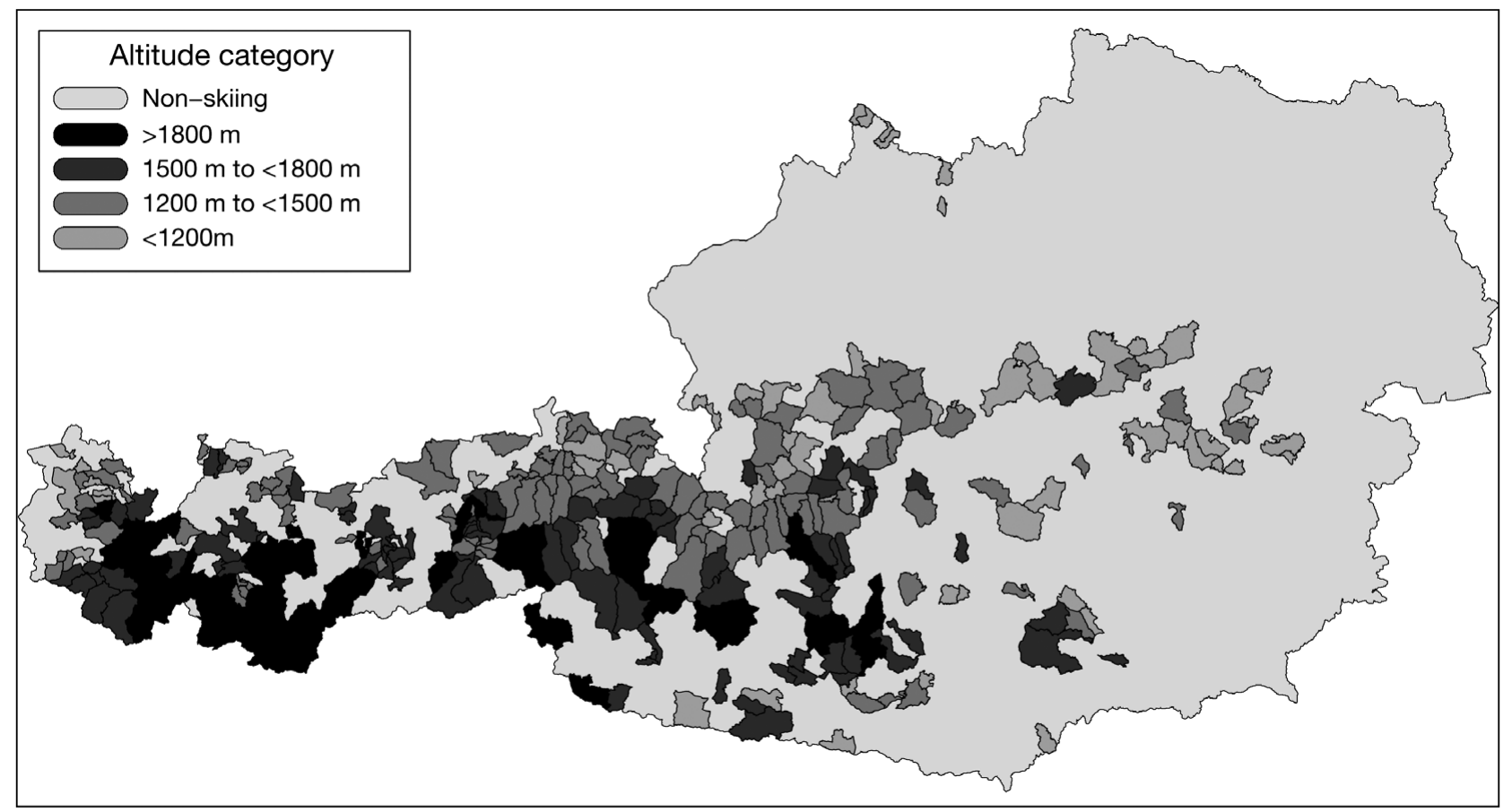

Fig. 1. Austrian municipalities categorized according to the mean altitudes of ski areas 
Based on the results from the snow cover model, several snow indices were calculated on a seasonal basis for the lowest and mean altitude of the ski areas: mean snow depth $\left(S_{\text {mean }}, \mathrm{cm}\right)$, days with snow depth $>1 \mathrm{~cm}$ $\left(\operatorname{Sday}_{1}, \mathrm{~d}\right)$ and days with snow depth $>30 \mathrm{~cm}\left(\operatorname{Sday}_{30}\right)$. In addition, for some analyses we considered mean air temperature $\left(T_{\text {mean }}{ }^{\circ} \mathrm{C}\right)$ as well as the urban snow conditions $\left(S d a y_{1, \text { cities }}\right)$ and weighted mean snow conditions, with the weights being the overnight stays $\left(\operatorname{Sday}_{1, \mathrm{AVG}}\right)$.

We conducted our analysis using all of these weather indices but, for the sake of brevity, we focus on the $S d a y_{1}$ index to illustrate our results for individual ski areas. We chose this index based on a comparison of data for 17 measurement stations, which are located close to the lowest altitudes of ski areas, with the respective snow indices from the snow cover model. This analysis revealed a systematic underestimation of snow depths by the snow cover model. Thus, in reality, the $S d a y_{1}$ index portrays higher snow depth than just $1 \mathrm{~cm}$. Furthermore, an evaluation of the model uncertainty shows smaller deviations from measurement data for $S d a y_{1}$ than for $S_{d a y_{30}}$ or $S_{\text {meani }}$ correlations between model and measurement data were also higher for this index.

Analyzing the snow indices in more detail, we see that the climatological mean of all of the snow indices, not surprisingly, increased with altitude. The standard deviation (SD) varied substantially across ski areas, with higher-lying areas generally exhibiting less data variability for $S d a y_{1}$ but more variability for $S d a y_{30}$ and $S_{\text {mean. }}$ All snow indices exhibited negative trends for the vast majority of areas, with more pronounced trends observed in higher-lying areas. Fig. 3 illustrates the climatological mean, SD and trend for $S d a y_{1}$ in the mean altitudes of ski areas.

Overall, we expect the number of overnight stays to be positively affected by good snow conditions, with lower-lying areas being particularly dependent. If there is enough snow depth in lower lying areas, tourists will tend to go there. This should be especially true for such ski areas in Tyrol, Salzburg and Vorarlberg, which are easy to reach from Germany, and for such ski areas in Lower and Upper Austria, which are closer to Vienna compared with competing destinations in Salzburg and Tyrol. By contrast, it is also expected that higher-lying areas benefit more from winters and preceding winters with bad snow conditions, as they are considered to be more snow reliable.

\subsection{Other data}

For the panel data models, we used several other non-climatic variables that are likely to have an impact on tourism demand. First, supply of accommodation

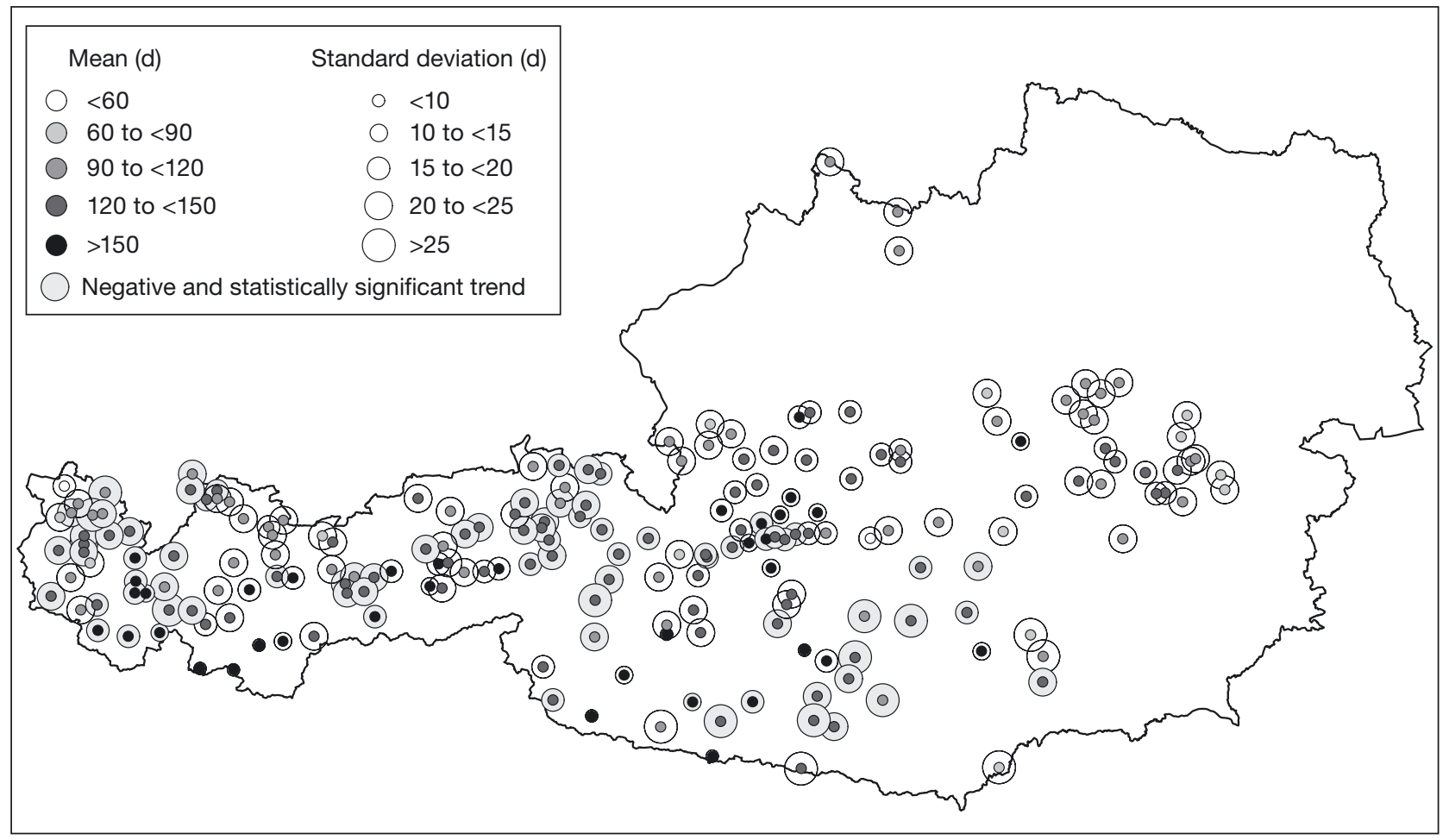

Fig. 3. Climatological mean, standard deviation and trends for days with snow depth $>1 \mathrm{~cm}$ for the mean altitude of ski areas in the winter seasons 1972/1973-2005/2006. Data source: ZAMG (2009) 
was considered by using the number of beds in a ski area (Statistics Austria 2008). Additional capacity is likely to enhance the number of overnight stays in an area. Furthermore, the tourism forecasting and demand literature suggests that a bundle of economic variables influences the level of overnight stays (see Song et al. 2009). We thus included income and price variables by using GDP, consumer price indices (CPI) and exchange rates (OECD 2008). We closely follow Luzzi \& Flückiger (2003) by calculating income and price variables weighted by the guests' origin in each ski area. The income index is expected to influence tourism demand positively whereas relative price levels are expected to influence tourism demand negatively.

\subsection{Time series regression models}

In order to estimate the impacts of weather conditions in each of the ski areas, we used an autoregressive distributed lag (ADL) model. In principal, our ski area specific model has the same form as the models used in Bigano et al. (2005) and Agnew \& Palutikof (2006), except that we worked on the local rather than on the national or provincial scale. Instead of putting the highly collinear weather indices into a single model, we used only one index at a time and repeated calculations for all indices. Accordingly, in order to explain variations in overnight stays in winter on a seasonal basis $t$ (nights (n) $_{t}$ our model contains lags of the dependent variable nights $_{t-1}$, nights $t_{t-2}$ ) as well as the respective meteorological variable $\left(\right.$ snow $\left._{t}\right)$ and its lag $\left(\right.$ snow $\left._{t-1}\right)$, and can be written for each of the $1, \ldots, n$ ski areas as:

$$
\begin{aligned}
\log \text { nights }_{t}= & \beta_{0}+\beta_{1} \log \text { nights }_{t-1}+\beta_{2} \log \text { nights }_{t-2}+ \\
& \beta_{3} \log \text { snow }_{t}+\beta_{4} \log \text { snow }_{t-1}+\varepsilon_{t}
\end{aligned}
$$

where $\varepsilon_{t}$ represents the error term and $\beta_{0}$ to $\beta_{4}$ the respective coefficients.

A lag length of 1 was chosen for snow $w_{t}$, whereas the dependent variable enters the equation with 2 lags. Dynamic modelling by including lagged dependent variables in the regression is recommended in the presence of temporal autocorrelation in the residuals and/or high persistency in the dependent variable. The inclusion of a lagged dependent variable then reduces the amount of potential spurious regression, which may lead to wrong inferences and potential inconsistent estimation. Apart from that, obtained autoregressive coefficients are often of interest by themselves, because they allow both tourist expectations and habit persistence to be taken into account. These behaviour patterns are expected to be stable, as people who have been on holiday to a particular destination and liked it tend to return to that destination. Uncertainty is reduced and knowledge about the destination spreads by word of mouth, and this may well play a more important role in destination selection than commercial advertising (Song et al. 2009).

We took the logarithm of overnight stays and the snow index. This is common in the literature for tourism demand data, because transforming to logarithms produces time series with approximately constant variance over time. Otherwise, it is often the case that the higher the level of a series rises, the greater the variation observed around that level. Taking logarithms for the snow index also enables us to interpret coefficients from the regression models directly as elasticities (log-log specification).

The model for each of the ski areas was tested for residual autocorrelation (Breusch 1978, Godfrey 1978), functional form (Ramsey 1969), heteroscedasticity (Breusch \& Pagan 1979) and the distribution of the residuals (Jarque \& Bera 1980). A model can be considered as statistically acceptable when none of the applied tests indicate a violation of the underlying assumptions. All tests were conducted with a significance level of $5 \%$.

The snow elasticities $\left(\beta_{3}\right)$ for each area give the percentage change in overnight stays for a $1 \%$ increase in snow days. However, it is important to note that a direct comparison of the elasticities of different ski areas is not particularly fruitful because of the variability in the original snow data. Therefore, the impact of a change in snow conditions in a ski area is given as the percentage change in overnight stays when the respective snow index varies by $1 \mathrm{SD}(\sigma)$. This gives the following formula:

$$
\text { impact }_{\text {snowchange }}=\beta_{3} \sigma_{\text {log snow }}=\frac{\% \Delta \text { nights }}{\% \Delta \text { snow }} \sigma_{\text {log snow }}
$$

Putting it differently, the impact of a 1 SD change measures not only the sensitivity of the examined demand indicator given by the demand elasticity but also the probability that a certain impact occurs. The probability of such a standard deviation change obviously depends on the distribution of the snow index. Under a normal distribution, the probability of a winter with a $>1$ SD decrease in the index would be $15.9 \%$. For the $S d a y_{1}$ index, for example, this is approximately true for the median ski area $(14.7 \%)$, but altogether the estimated probabilities vary with the skewness and kurtosis of the respective indices. As an alternative to $\mathrm{SD}$, we could estimate some other risk measure, e.g. the 5 or $10 \%$ quantile, and speaking in the language of financial risk management, it could be referred to as 'overnight stays at risk'. However, in this case more attention would need to be placed on the modelling of the weather index, as the use of 34 seasonal observations makes it more difficult to estimate quantiles, particularly because here it is the tails of the distributions which are of more interest. 


\subsection{Panel data models}

In order to estimate the impact of the variables on tourism demand in ski areas, the ADL model type, as used for the time series regressions before, was also applied to the whole data set, making up a panel with 185 cross-section units and a time dimension of 34 units. As this model gives more degrees of freedom, we additionally used variables for the supply of accommodation $\left(b e d s_{i t}\right)$, income $\left(g d p_{i t}\right)$ and prices $\left(p p_{i t}\right)$, where the subscripts $i$ and $t$ represent the specific ski area and the season respectively. Therefore, our model specification has a certain resemblance to the model presented in Garín-Muñoz \& Montero-Martín (2007), except that we include $b^{2} s_{i t}$ and $s n o w_{i t}$ as additional determinants. Accordingly, the general model setup for the panel data estimations can be written as:

$$
\begin{aligned}
\log \text { nights }_{i t}= & \beta_{0}+\beta_{1} \log \text { nights }_{i t-1}+\beta_{2} \log \text { nights }_{i t-2}+ \\
& \beta_{3} \log \text { snow }_{i t}+\beta_{4} \log b e d s_{i t}+\beta_{5} \log g d p_{i t} \\
& +\beta_{6} \log p p_{i t}+\mu_{i}+\lambda_{t}+\varepsilon_{i t}
\end{aligned}
$$

where the impact of the unobserved heterogeneity and the common time trend is captured by $\mu_{i}$ and $\lambda_{t}$, respectively.

An important motivation behind the utilization of such a cross-section panel is simply the widening of the database. By capturing heteroscedasticity not only across time but also across regions, panel data models are more informative, in the sense that they capture a higher variability of the data. This helps to overcome the spurious impact of collinearity among variables (see Baltagi 2008), a major problem in time series regression analysis. What is more, the availability of 2 dimensions allows us to control for 2 potential omitted variable biases, one resulting from unobserved individual, time constant effects such as landscape, the other resulting from an unobserved trend component in the dependent variable, common for all ski areas.

For purposes of comparison, a range of different panel models will be estimated in this paper, some which are expected to be systematically biased and inconsistent. Panel data techniques follow, to a certain extent, the work of Garín-Muñoz \& Montero-Martín (2007) and Sequeira \& Nunes (2008), except that we assessed some more recent cross-section panel estimators.
A summary of the applied models is given in Table 1. Estimated models can be distinguished according to either the transformation method they use to remove unobserved effects or their consistency properties. Consistent and unbiased estimation of dynamic panel model specifications requires the use of generalized methods of moments (GMM) or specific bias-corrected fixed effects estimators.

We first estimated a pooled model with an ordinary least squares (OLS) estimator (POOLED). It represents the most restricted model, as it assumes that all coefficients including the intercept are constant for all ski areas over time. We then applied a fixed effects model (FE) and a 2-way fixed effects model (FE_tw). As opposed to the pooled model, they both account for unobserved individual, time-constant fixed effects by using the so-called within-transformation. Therefore, all observations enter the equation in deviation of the individual time average. As a consequence, it simply conducts a demeaning of the data, which eliminates the unobserved time-constant individual effect component before assessing OLS. Another, perhaps more intuitive way of obtaining the same regression coefficients would be to include a set of dummy variables identifying each cross-section unit, what is known as the least squares dummy variables (LSDV) estimator. The 2-way fixed effects model additionally includes time dummies in order to remove the common trend component from the errors. This is recommended by Roodman (2009) and is also a standard procedure for all GMMs estimated in this paper.

However, when one attempts to capture dynamic effects by inclusion of a lagged dependent variable, estimations of the POOLED, FE and 2-way FE models become inconsistent, because the strict exogeneity assumption for the regressors is then violated. Nickell (1981) was the first to estimate the size of this bias for the fixed effects estimator. Such bias approximations are crucial for the branch of bias-corrected fixed effects models, which deliver unbiased and consistent estimation coefficients by correcting them according to their expected biases. In the present study, the biascorrected fixed effects estimator from Bruno (2005)

\begin{tabular}{|c|c|c|c|c|}
\hline Model & Type & Transformation & Regressors & Consistency \\
\hline POOLED & Pooled & None & $y_{i, t-1}, x_{i}, 1, \lambda_{t}$ & Inconsistent/biased \\
\hline $\mathrm{FE}$ & Fixed effects & Within & $y_{i, t-1}, x_{i}, 1, \mu_{i}$ & Inconsistent/biased \\
\hline FE_tw & 2-way fixed effects & Within & $y_{i, t-1}, x_{i}, 1, \mu_{i}, \lambda_{t}$ & Inconsistent/biased \\
\hline FE_tw_bc & Bias corrected 2-way fixed effects & Within & $y_{i, t-1}, x_{i}, 1, \mu_{i}, \lambda_{t}$ & Consistent/unbiased \\
\hline DIFF-GMM & First-difference GMM (one-step) & $\Delta$ & $\Delta y_{i, t-1}, \Delta x_{i}, 1, \lambda_{t}$ & Consistent/unbiased \\
\hline SYS-GMM & System GMM (one-step) & $\Delta$ & $\Delta y_{i, t-1}, \Delta x_{i}, y_{i, t-1}, 1, \lambda_{t}$ & Consistent/unbiased \\
\hline
\end{tabular}
was applied (FE_tw_bc).

Table 1. Summary of the panel data estimation procedures. GMM: generalized methods of moments. $\Delta$ : first-difference 
Efficient and reliable estimates can be also obtained by using a GMM framework. A common linear GMM estimator for cross-section panels (with short time dimension T) is the first-difference GMM (DIFF-GMM) proposed by Arellano \& Bond (1991). Individual fixed effects are eliminated by differencing instead of within-transforming. Differenced variables that are not strictly exogenous are instrumented by lagged levels of the variable itself. The estimation procedure is then similar to the generalized least squares (GLS) procedure but, whereas GLS minimizes the weighted sum of the second moments of the residuals, GMM minimizes the weighted sum of the covariance structure of the moments.

An augmented version of the first-difference GMM, the so-called System-GMM, outlined in Arellano \& Bover (1995) and fully developed in Blundell \& Bond (1998), was also assessed. The System-GMM tackles the weak instrument problem, which implies that differences of persistent time series are near to innovations and, therefore, difficult to instrument. Following Roodman (2009, p. 114), in the case of such persistent variables, 'past changes may [...] be more predictive of current levels than past levels are of current changes'. Therefore, the System-GMM builds up a system of 2 equations, the difference equation, as before, and the level equation, where endogenous variables in their levels are instrumented by lagged differences.

The System-GMM was calculated in its standard version, using all available lags of the dependent variable as GMM-instrumentals (SYS-GMM). Because performance of the GMMs depends on the validity of the instruments, which becomes more unreliable when exploiting such a large set of moment conditions, a more restricted model was estimated, using only lags 4 to 7 of the dependent variable as GMM-instrumentals (SYS-GMM_valid). In addition, in order to relax the problematic assumption of strict exogeneity for the variable $g d p_{i t}$, we included a model where $g d p_{i t}$ is not treated as standard but as a GMM-style instrumental variable (SYS-GMM_gdp).

\subsection{Analyzing the temporal evolution}

In the literature dealing with weather impacts on tourism demand, one research question has been ignored so far; namely, the extent to which sensitivity varies over time. Our panel data approach allows us to study this temporal dimension in more detail. To do this, the data set of 34 seasons was divided into 3 periods consisting of 10,11 and 11 time points, respectively (the lagged dependent variables make it necessary to dispense with 2 time points). Separate models were estimated for each time period, using the FE_tw_bc and the SYS-GMM_gdp models. For these separate models with only 10, 11 and 11 time points (as described in the caption of Table 4), respectively, the relatively large cross-section dimension of 185 makes the GMM estimator used for the SYS-GMM_gdp model preferable to the FE_tw_bc model.

We further studied the temporal dimension by assessing a variable coefficient model. For each season, a regression over all cross-section units was calculated based on the FE_tw model setup. We are aware that such cross-section estimations contain systematic bias and may need to be adjusted accordingly.

Moreover, we analyzed the effects separately for 2 extreme seasons; namely, the warm and snow-poor winter seasons 1989/1990 and 2006/2007. In these seasons, the number of snow days was 22 and $29 \%$ below average, respectively, which corresponds to 1.5 and 1.9 SD.

\section{RESULTS}

In this section, we discuss the estimation results from the time series regression and the panel data models. We first present the results for individual ski areas and on the provincial level and focus here on the interpretation of the impacts under a $1 \mathrm{SD}$ change in the snow indices. Then we give the results of the panel estimations and describe the temporal evolution of the snow coefficients.

\subsection{Time series regression models}

We begin with describing the results obtained for the $S d a y_{1}$ index in the mean altitude of ski areas and then compare them to the results for other meteorological indices. First of all, the high significance of the lagged dependent variables in the models (174 out of the 185 nights $t_{t-1}$ coefficients were significant at the $10 \%$ level) show that habit persistence and tourist expectations also play an important role on a local scale. As suggested by theory, the coefficient sums of nights $t_{t-1}$ and nights $_{t-2}$ are positive, but smaller than 1 (median ski area $=0.64$ ), whereby values close to 1 indicate more stable behaviour patterns.

As expected, the snow conditions $\left(\right.$ snow $\left._{t}\right)$ had a predominantly positive impact on tourism demand in Austrian ski areas. The ADL model, applied to 185 ski areas, revealed 139 positive and 46 negative coefficients (45 positive and 3 negative coefficients were significant at the $10 \%$ level). It is noteworthy that these results indicate the exact opposite of what we would expect from the static simple regression model often used for explorative analysis of weather dependen- 
cies. In fact, the static simple regression model would wrongly leave us with 143 negative and 42 positive coefficients, presumably resulting from spurious correlations between the mostly positive-trending nights $t_{t}$ and negative-trending snow ${ }_{t}$.

The estimated coefficient $\beta_{3}$, which can be interpreted as snow elasticity of demand, was well below 1 for all areas. This means that, in the short term, overnight stays are relatively inelastic with respect to snow conditions, i.e. a $1 \%$ decrease in the snow index results in a $<1 \%$ decrease in overnight stays. It is important to note, however, that because the season-toseason variability of the snow index is relatively high ( $12 \%$ for the average area) the resulting economic impacts were not negligible, despite the low elasticity.

Fig. 4 gives the impact of a $1 \mathrm{SD}$ change in $S d a y_{1}$ for the mean altitudes of ski areas. The results widely confirm previously described regional demand patterns. On the one hand, coefficients were significant and positive for a range of areas with a reputation to be particularly dependent on snow conditions. These are rather lower-lying areas on the north side of the main chain of the Alps, e.g. in Central Vorarlberg, the Tannheimer Valley, the Wilder Kaiser/Kitzbüheler Alps region and in Lower Austria. For several other regions, such as the provinces of Salzburg and Carinthia, area-specific coefficients were predominantly positive, though not significant in most cases. On the other hand, coefficients were significant and negative for 2 Tyrolean areas with particularly good snow conditions, namely Galtür and Tux/Hintertux, but, altogether, overnights stays in higher-lying areas showed comparatively little reaction to changes in snow conditions.

Redoing our analysis using other meteorological indices widely confirmed these patterns for $S d a y_{1}$ (mean altitude). Specifically, replacing $S d a y_{1}$ with $S d_{a y}{ }_{30}, S_{\text {mean }}$ or the respective indices for the lowest altitude of ski areas did not change these broad patterns, whereas the estimates for some individual areas differed quite substantially. When using $T_{\text {mean }}$ in most cases the signs of estimated coefficients were reversed compared to those from snow indices. This is to be expected, as temperature is generally negatively related to snow conditions. However, temperature estimates were much less significant compared to the snow indices considered. Where available, snow data should thus generally be preferred to temperature data in studies of climate change impacts on winter tourism.

Interestingly, there is clear-cut evidence in our data that, although higher-lying areas do not really depend on their own snow conditions, they are heavily influenced by snow conditions in other ski areas. For example, we found a significant negative relationship between overnight stays and weighted-average Austrian snow conditions $\left(\right.$ Sday $\left._{1, \mathrm{AVG}}\right)$ for 6 out of 8 areas with access to glaciers.

Furthermore, we found less convincing results for the so-called backyard hypothesis [see Hamilton et al. (2007) for related data on Boston and surrounding US ski areas]. Considering the snow conditions in each of the 5 major Austrian cities (Vienna, Graz, Linz, Salzburg and Innsbruck), we found positive relationships

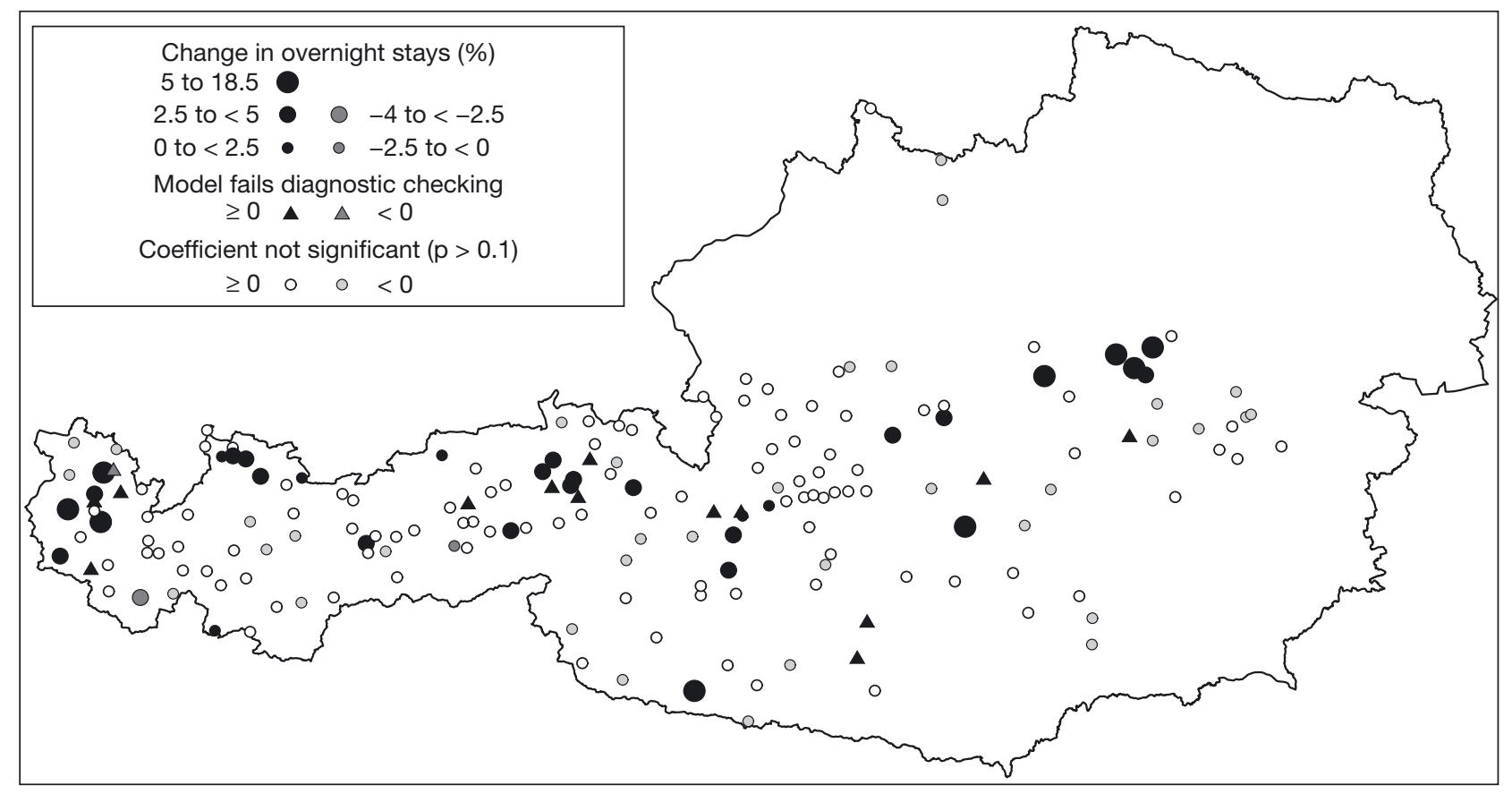

Fig. 4. Impact of a $1 \mathrm{SD}$ change in days with snow depth $>1 \mathrm{~cm}$ on overnight stays 
between $S d a y_{1}$ in the respective cities and overnight stays in nearby areas in some cases. These results can largely be explained by positive correlations between snow conditions in the cities and nearby areas, and it is therefore unknown whether it is really the urban snow conditions or rather its correlation with mountain snow conditions that drives these effects. Some patterns can also be found for areas where correlations between snow conditions hardly exist. Most notably, snow conditions in Vienna, Graz and Linz seem to positively influence overnight stays in Carinthia. However, we are aware that analyzing the backyard effect for individual ski areas in more detail would require data on urban snow conditions in source markets, the consideration of the respective shares on total guests, which differ substantially between areas and over time, and calculations on a daily or monthly level.

In general, patterns are more unclear for regions with typically small ski areas, most notably in Eastern Austria. Indeed, with our modelling approach, the larger an area is, the more likely is dependence on snow conditions to be significant. We surmise that this can be explained by larger modelling uncertainties for smaller areas. The smaller an area, the higher the variability in demand, and the more important the noninclusion of a range of unknown local non-climatic factors affecting the development of overnight stays. Note that several individual areas in Western Austria account for more overnight stays than all the areas in provinces such as Lower or Upper Austria.

Consequently, when grouping all areas on a provincial level, a significant positive dependency on snow conditions can be found for each of the 7 winter sport provinces (Table 2). Impacts are below average in the western provinces of Tyrol and Vorarlberg, where most of the overnight stays take place in higher-lying areas. By contrast, impacts are by far the highest in the provinces of Carinthia and Lower Austria. Interestingly, whereas areas in Lower Austria are particularly low-lying and exhibit less favourable snow conditions compared to other provinces, areas in Carinthia are generally higher-lying and snow reliable. However, in both of these provinces, climate conditions are less related to those in Tyrol and Salzburg compared with

Table 2. Impact of a $1 \mathrm{SD}$ change in different weather indices on overnight stays in ski areas (parentheses: $t$-statistics). Sday days with snow depth $>1 \mathrm{~cm}(\mathrm{~d}) ; S d_{2} y_{30}$ : days with snow depth $>30 \mathrm{~cm} ; S_{\text {mean }}$ : mean snow depth $(\mathrm{cm}) ; T_{\text {mean }}$ : mean air temperature $\left({ }^{\circ} \mathrm{C}\right) ; \operatorname{Sday}_{1, \mathrm{AVG}}$ : weighted mean $\operatorname{Sday}_{1}(\mathrm{~d})$, with the weights being the overnight stays. ${ }^{*} \mathrm{p}<0.1,{ }^{* *} \mathrm{p}<0.05,{ }^{* * *} \mathrm{p}<0.01$. Other estimates from the regression models are not displayed for space reasons

\begin{tabular}{|c|c|c|c|c|c|c|c|c|}
\hline \multirow[t]{2}{*}{ Ski area } & \multicolumn{2}{|c|}{$-S d a y_{1}-$} & \multicolumn{2}{|c|}{$\mathrm{Sday}_{30}$} & \multicolumn{2}{|c|}{$-S_{\text {mean }}-$} & \multirow{2}{*}{$\begin{array}{c}T_{\text {mean }} \\
\text { Mean } \\
\text { altitude }\end{array}$} & \multirow{2}{*}{$\begin{array}{c}\text { Sday }_{1, \mathrm{AVG}} \\
\text { Mean } \\
\text { altitude }\end{array}$} \\
\hline & $\begin{array}{l}\text { Mean } \\
\text { altitude }\end{array}$ & $\begin{array}{l}\text { Lowest } \\
\text { altitude }\end{array}$ & $\begin{array}{l}\text { Mean } \\
\text { altitude }\end{array}$ & $\begin{array}{l}\text { Lowest } \\
\text { altitude }\end{array}$ & $\begin{array}{l}\text { Mean } \\
\text { altitude }\end{array}$ & $\begin{array}{l}\text { Lowest } \\
\text { altitude }\end{array}$ & & \\
\hline Austria & $\begin{array}{l}1.47^{* *} \\
(2.62)\end{array}$ & $\begin{array}{c}1.07^{*} \\
(1.94)\end{array}$ & $\begin{array}{l}1.27^{* *} \\
(2.16)\end{array}$ & $\begin{array}{l}1.11^{*} \\
(2.00)\end{array}$ & $\begin{array}{c}1.57^{* * *} \\
(2.87)\end{array}$ & $\begin{array}{l}1.38^{* *} \\
(2.61)\end{array}$ & $\begin{array}{l}-0.99 \\
(-1.68)\end{array}$ & $\begin{array}{l}1.47^{* *} \\
(2.62)\end{array}$ \\
\hline \multicolumn{9}{|l|}{ Provinces } \\
\hline Carinthia & $\begin{array}{l}3.98^{* * *} \\
(3.18)\end{array}$ & $\begin{array}{l}4.59^{* * *} \\
(4.39)\end{array}$ & $\begin{array}{l}3.64^{* *} \\
(2.67)\end{array}$ & $\begin{array}{l}3.37^{* *} \\
(2.59)\end{array}$ & $\begin{array}{c}4.51^{* * *} \\
(3.43)\end{array}$ & $\begin{array}{l}4.32^{* * *} \\
(3.42)\end{array}$ & $\begin{array}{l}-4.12^{* * *} \\
(-3.57)\end{array}$ & $\begin{array}{c}0.86 \\
(0.62)\end{array}$ \\
\hline Lower Austria & $\begin{array}{l}2.41^{* *} \\
(2.45)\end{array}$ & $\begin{array}{l}2.66^{* * *} \\
(2.83)\end{array}$ & $\begin{array}{l}2.54^{* *} \\
(2.39)\end{array}$ & $\begin{array}{l}2.79^{* *} \\
(2.74)\end{array}$ & $\begin{array}{c}2.86^{* * *} \\
(3.06)\end{array}$ & $\begin{array}{l}2.99^{* * *} \\
(3.22)\end{array}$ & $\begin{array}{l}-1.60 \\
(-1.53)\end{array}$ & $\begin{array}{l}3.34^{* * *} \\
(3.70)\end{array}$ \\
\hline Upper Austria & $\begin{array}{l}1.42^{*} \\
(1.84)\end{array}$ & $\begin{array}{l}1.64^{*} \\
(2.02)\end{array}$ & $\begin{array}{l}1.73^{* *} \\
(2.21)\end{array}$ & $\begin{array}{c}0.94 \\
(1.09)\end{array}$ & $\begin{array}{c}2.07^{* * *} \\
(2.81)\end{array}$ & $\begin{array}{l}1.88^{* *} \\
(2.47)\end{array}$ & $\begin{array}{l}-0.63 \\
(-0.67)\end{array}$ & $\begin{array}{l}2.70^{* * *} \\
(3.02)\end{array}$ \\
\hline Salzburg & $\begin{array}{l}2.17^{* * *} \\
(2.82)\end{array}$ & $\begin{array}{c}1.22 \\
(1.59)\end{array}$ & $\begin{array}{l}1.91^{* *} \\
(2.47)\end{array}$ & $\begin{array}{l}1.75^{* *} \\
(2.30)\end{array}$ & $\begin{array}{c}2.36^{* * *} \\
(3.25)\end{array}$ & $\begin{array}{l}2.11^{* * *} \\
(3.01)\end{array}$ & $\begin{array}{l}-1.24 \\
(-1.55)\end{array}$ & $\begin{array}{l}2.18^{* *} \\
(2.77)\end{array}$ \\
\hline Styria & $\begin{array}{c}0.90^{*} \\
(1.86)\end{array}$ & $\begin{array}{c}0.90^{*} \\
(1.85)\end{array}$ & $\begin{array}{l}1.18^{* *} \\
(2.29)\end{array}$ & $\begin{array}{c}0.74 \\
(1.34)\end{array}$ & $\begin{array}{l}1.12^{* *} \\
(2.18)\end{array}$ & $\begin{array}{l}1.10^{* *} \\
(2.13)\end{array}$ & $\begin{array}{l}-0.56 \\
(-1.02)\end{array}$ & $\begin{array}{l}1.06^{*} \\
(1.99)\end{array}$ \\
\hline Tyrol & $\begin{array}{c}1.14^{*} \\
(1.86)\end{array}$ & $\begin{array}{c}0.73 \\
(1.19)\end{array}$ & $\begin{array}{l}1.07^{*} \\
(1.74)\end{array}$ & $\begin{array}{c}0.87 \\
(1.48)\end{array}$ & $\begin{array}{l}1.31^{* *} \\
(2.19)\end{array}$ & $\begin{array}{l}1.02^{*} \\
(1.73)\end{array}$ & $\begin{array}{l}-0.63 \\
(-0.99)\end{array}$ & $\begin{array}{l}1.06^{*} \\
(1.71)\end{array}$ \\
\hline Vorarlberg & $\begin{array}{l}1.37^{* *} \\
(2.58)\end{array}$ & $\begin{array}{l}1.06^{*} \\
(2.02)\end{array}$ & $\begin{array}{c}0.76 \\
(1.32)\end{array}$ & $\begin{array}{c}0.74 \\
(1.36)\end{array}$ & $\begin{array}{l}0.94^{*} \\
(1.71)\end{array}$ & $\begin{array}{c}0.89 \\
(1.68)\end{array}$ & $\begin{array}{l}-0.56 \\
(-0.93)\end{array}$ & $\begin{array}{l}1.60^{* * *} \\
(3.06)\end{array}$ \\
\hline \multicolumn{9}{|l|}{ Mean altitude (m) } \\
\hline$<1200$ & $\begin{array}{l}1.59^{* *} \\
(2.77)\end{array}$ & $\begin{array}{l}1.48^{* *} \\
(2.59)\end{array}$ & $\begin{array}{l}1.61^{* * *} \\
(2.86)\end{array}$ & $\begin{array}{c}1.34^{* *} \\
(2.33)\end{array}$ & $\begin{array}{l}2.11^{* *} \\
(4.14)\end{array}$ & $\begin{array}{l}1.87^{* * *} \\
(3.57)\end{array}$ & $\begin{array}{l}-0.98 \\
(-1.58)\end{array}$ & $\begin{array}{l}1.96^{* * *} \\
(3.27)\end{array}$ \\
\hline 1200 to $<1500$ & $\begin{array}{l}2.30^{* *} \\
(3.00)\end{array}$ & $\begin{array}{l}1.99^{* * *} \\
(2.80)\end{array}$ & $\begin{array}{l}2.33^{* * *} \\
(3.17)\end{array}$ & $\begin{array}{l}1.96^{* *} \\
(2.67)\end{array}$ & $\begin{array}{l}2.72^{* *} \\
(4.01)\end{array}$ & $\begin{array}{l}2.52^{* * *} \\
(3.90)\end{array}$ & $\begin{array}{l}-1.33 \\
(-1.60)\end{array}$ & $\begin{array}{l}2.53^{* * *} \\
(3.28)\end{array}$ \\
\hline 1500 to $<1800$ & $\begin{array}{l}2.25^{* *} \\
(3.74)\end{array}$ & $\begin{array}{l}1.34^{* *} \\
(2.12)\end{array}$ & $\begin{array}{l}1.73^{* *} \\
(2.72)\end{array}$ & $\begin{array}{l}1.39^{* *} \\
(2.20)\end{array}$ & $\begin{array}{c}2.11^{* * *} \\
(3.55)\end{array}$ & $\begin{array}{l}1.69^{* * *} \\
(2.89)\end{array}$ & $\begin{array}{l}-1.45^{* *} \\
(-2.26)\end{array}$ & $\begin{array}{l}2.11^{* * *} \\
(3.48)\end{array}$ \\
\hline$>1800$ & $\begin{array}{l}-0.38 \\
(-0.69)\end{array}$ & $\begin{array}{l}-0.48 \\
(-0.88)\end{array}$ & $\begin{array}{l}-0.56 \\
(-0.99)\end{array}$ & $\begin{array}{l}-0.49 \\
(-0.96)\end{array}$ & $\begin{array}{c}-0.48 \\
(-0.89)\end{array}$ & $\begin{array}{l}-0.59 \\
(-1.12)\end{array}$ & $\begin{array}{c}0.35 \\
(0.66)\end{array}$ & $\begin{array}{l}-0.69 \\
(-1.30)\end{array}$ \\
\hline
\end{tabular}


other provinces, where most of the skiing activities take place ( $70 \%$ of the market share). Therefore, substitution effects between these regions might be one possible explanation for the relatively high coefficients.

All of these results on the provincial level are robust to using different snow indices, except for the weightedaverage Austrian snow conditions ( $S d a y_{1,} \mathrm{AVG}_{\mathrm{V}}$ ). Especially for the provinces of Lower Austria, Upper Austria and Vorarlberg, Sday ${ }_{1, \mathrm{AVG}}$ seems to be much more important than the snow conditions in their own areas. We suppose that this again results from the outstanding position of the provinces of Tyrol and Salzburg in the market share and the media coverage of winter tourism. If snow conditions are good there, they are believed to be good in Austria in general and thus they positively impact overnight stays in other provinces. This might not be the case for the southern province of Carinthia, however, for which the estimated impact of $S d a y_{1, \mathrm{AVG}}$ is extraordinary low.

Apart from that, aggregating areas according to their mean altitude $(<1200,1200$ to $<1500,1500$ to $<1800$ and $\geq 1800 \mathrm{~m}$ ) widely confirms the results for individual ski areas: areas below $1800 \mathrm{~m}$ significantly depend on their own snow conditions, but this is not the case for areas above $1800 \mathrm{~m}$.

\subsection{Panel data models}

All in all, the FE_tw_bc and the SYS-GMM_gdp models have proven to be the most adequate models in our analysis. Both estimators are systematically unbiased and consistent and deliver reasonable results. One drawback of the SYS-GMM_gdp model is probably the inclusion of a relatively large number of instrumental variables, which increases efficiency but may also enhance finite sample bias. However, this bias does not seem to be pronounced in our model, considering the similar values for the sum of the dependent variable coefficients obtained for both models.

Table 3 compares the general model estimation results with the panel data set. Coefficient signs match expectations and were highly significant for nights $s_{i t-1}$, nights $_{i t-2}$ and snow ${ }_{i t}$. For the lagged dependent variables, a value between 0 and 1 was expected and found for all models. This confirms the results from the ADL model and indicates a relatively high level of persistence for overnight stays. As for the ADL model, the respective coefficient for snow $_{i t}$ can be interpreted as elasticity and ranged from 0.052 to 0.156 , with estimates from the most reliable approaches in the lower range (0.052 and 0.094). This bandwidth corresponds

Table 3. General model estimation results with the complete panel data set. $t$-statistics are given in parentheses and all are robust to heteroskedasticity. Variables are defined in Section 2.6. Tests follow the convention in the literature. Rho is the fraction of variance due to fixed effects $\mu_{i} \cdot{ }^{*} \mathrm{p}<0.1,{ }^{* *}<0.05,{ }^{* * *}<0.01$. All regressions except FE include time dummies. Time dummy estimates are not displayed for space reasons. -: tests not relevant for this model

\begin{tabular}{|c|c|c|c|c|c|c|c|c|}
\hline $\begin{array}{l}\text { Variable/ } \\
\text { Test }\end{array}$ & POOLED & $\mathrm{FE}$ & FE_tw & FE_tw_bc & $\begin{array}{l}\text { DIFF- } \\
\text { GMM }\end{array}$ & $\begin{array}{l}\text { SYS- } \\
\text { GMM }\end{array}$ & $\begin{array}{c}\text { SYS-GMM } \\
\text { _valid }\end{array}$ & $\begin{array}{c}\text { SYS-GMM } \\
\text { _gdp }\end{array}$ \\
\hline $\log n_{i g h t} s_{i t-1}$ & $\begin{array}{c}0.718^{* * *} \\
(11.97)\end{array}$ & $\begin{array}{c}0.610^{* * *} \\
(10.46)\end{array}$ & $\begin{array}{c}0.597^{* * *} \\
(10.57)\end{array}$ & $\begin{array}{c}0.637^{* * *} \\
(67.17)\end{array}$ & $\begin{array}{c}0.475^{* * *} \\
(6.43)\end{array}$ & $\begin{array}{c}0.638^{* * *} \\
(11.96)\end{array}$ & $\begin{array}{c}0.599^{* * *} \\
(4.76)\end{array}$ & $\begin{array}{c}0.639^{* * *} \\
(11.48)\end{array}$ \\
\hline $\log$ nights $_{i t-2}$ & $\begin{array}{c}0.214^{* * *} \\
(3.87)\end{array}$ & $\begin{array}{c}0.173^{* * *} \\
(3.76)\end{array}$ & $\begin{array}{c}0.186^{* * *} \\
(4.32)\end{array}$ & $\begin{array}{c}0.160^{* * *} \\
(16.63)\end{array}$ & $\begin{array}{c}0.166^{* * *} \\
(5.32)\end{array}$ & $\begin{array}{c}0.164^{* * *} \\
(3.92)\end{array}$ & $\begin{array}{c}0.270^{* * *} \\
(3.88)\end{array}$ & $\begin{array}{c}0.183^{* * *} \\
(3.72)\end{array}$ \\
\hline $\log s_{n o w}$ & $\begin{array}{c}0.062^{* * *} \\
(5.03)\end{array}$ & $\begin{array}{c}0.068^{* * *} \\
(4.61)\end{array}$ & $\begin{array}{c}0.052^{* *} \\
(2.5)\end{array}$ & $\begin{array}{c}0.052^{* * *} \\
(3.46)\end{array}$ & $\begin{array}{c}0.059^{* * *} \\
(2.81)\end{array}$ & $\begin{array}{c}0.076^{* * *} \\
(3.78)\end{array}$ & $\begin{array}{c}0.156^{* *} \\
(2.05)\end{array}$ & $\begin{array}{c}0.094^{* * *} \\
(5.9)\end{array}$ \\
\hline $\log b e d s_{i t}$ & $\begin{array}{c}0.085^{* * *} \\
(7.39)\end{array}$ & $\begin{array}{c}0.112^{* * *} \\
(5.47)\end{array}$ & $\begin{array}{c}0.131^{* * *} \\
(5.76)\end{array}$ & $\begin{array}{c}0.117^{* * *} \\
(10.2)\end{array}$ & $\begin{array}{c}0.200^{* * *} \\
(4.47)\end{array}$ & $\begin{array}{c}0.200^{* * *} \\
(6.32)\end{array}$ & $\begin{array}{l}0.139 \\
(1.36)\end{array}$ & $\begin{array}{c}0.218^{* * *} \\
(7.41)\end{array}$ \\
\hline $\log g d p_{i t}$ & $\begin{array}{l}0.036 \\
(0.68)\end{array}$ & $\begin{array}{l}0.011 \\
(1.26)\end{array}$ & $\begin{array}{c}0.410^{* * *} \\
(3.26)\end{array}$ & $\begin{array}{c}0.439^{* * *} \\
(5.87)\end{array}$ & $\begin{array}{l}0.985 \\
(1.45)\end{array}$ & $\begin{array}{c}0.683 \\
(1.5)\end{array}$ & $\begin{array}{l}0.361 \\
(0.93)\end{array}$ & $\begin{array}{c}0.553^{* * *} \\
(2.61)\end{array}$ \\
\hline $\log p p_{i t}$ & $\begin{array}{c}-0.041^{* * *} \\
(-3.35)\end{array}$ & $\begin{array}{c}-0.036^{* * *} \\
(-2.83)\end{array}$ & $\begin{array}{c}-0.029^{* *} \\
(-2.24)\end{array}$ & $\begin{array}{c}-0.028^{* *} \\
(-2.30)\end{array}$ & $\begin{array}{l}-0.021 \\
(-0.32)\end{array}$ & $\begin{array}{l}-0.011 \\
(-0.17)\end{array}$ & $\begin{array}{l}-0.035 \\
(-0.61)\end{array}$ & $\begin{array}{l}0.008 \\
(0.28)\end{array}$ \\
\hline $\mathrm{R}^{2}$ within & - & 0.776 & 0.784 & - & - & - & - & - \\
\hline $\operatorname{Corr}\left(\mu_{i}, X b\right)$ & - & 0.955 & 0.926 & - & - & - & - & - \\
\hline Rho & - & 0.639 & 0.604 & - & - & - & - & - \\
\hline Pesaran AR(1) & - & $75.4^{* * *}$ & $3^{* * *}$ & - & - & - & - & - \\
\hline Diff AR(2) & - & - & - & - & -0.203 & 0.88 & 0.175 & 0.728 \\
\hline Sargan test & - & - & - & - & $<0.001$ & $<0.001$ & $<0.001$ & $<0.001$ \\
\hline Hansen test & - & - & - & - & 1 & 1 & 0.143 & 1 \\
\hline Diff_Sarg IV & - & - & - & - & - & 1 & 0.672 & 1 \\
\hline Diff_Sarg GMM & - & - & - & - & - & 1 & 0.372 & 1 \\
\hline No. of instruments & - & - & - & - & 562 & 594 & 147 & 893 \\
\hline No. of groups & 185 & 185 & 185 & - & 185 & 185 & 185 & 185 \\
\hline No. of observations & 5920 & 5920 & 5920 & 5920 & 5735 & 5920 & 5920 & 5920 \\
\hline
\end{tabular}


to a $0.6-1.9 \%$ change in overnight stays for a $1 \mathrm{SD}$ change in snow conditions.

The variable $b d s_{i t}$ was also highly significant (except in the SYS-GMM_valid model), which leads us to reject considerations about potential multicollinearity. For the economic variables $g d p_{i t}$ and $p p_{i t}$, coefficients were less reliable and were only significant for some model specifications (most notably for the FE_tw and FE_tw_bc models). In particular, relative purchasing power $\left(p p_{i t}\right)$ did not seem to play a crucial role in our model, probably owing to the similarity of price developments in Germany, from where most visitors came. Another reason might also be that the CPI has been used for constructing this variable instead of some tourism price index. Such an index would ideally include regional accommodation, transport and ski lift prices, but this data cannot be obtained for the given time period and number of observations.

For the variable $g d p_{i t}$, it is interesting to compare the coefficient of adjustment and the income elasticities from these 2 models with other panel estimations of tourism demand available in the literature (GarínMuñoz \& Montero-Martín 2007). The coefficient of adjustment describes the speed of adjustment result- ing from changes in the exogenous variables. It can be obtained by subtracting the total of the lagged dependent variables from 1. Long-term coefficients are then obtained by dividing (short-term) coefficients with the coefficient of adjustment. Doing so, we found a relatively high short-term robustness with respect to external effects. The respective model adjustment coefficients of 0.18 and 0.21 show that approximately $20 \%$ of the adjustment of tourism to changes in the variables took place within the first $2 \mathrm{yr}$. The respective longterm income elasticities of 2.18 and 3.01 are in line with other studies (see Garín-Muñoz \& MonteroMartín 2007, Song et al. 2009) and reveal that demand in Austrian ski areas is strongly income elastic, as is common for luxury goods.

\subsection{Analyzing the temporal evolution}

Results for the separate time period panel data models are listed in Table 4. While in the SYS-GMM_gdp model the overall trend appears ambiguous for most of the variables, a decline in the snow $w_{i t}$ coefficient can be observed in the model, from 0.168 in Period 1 to 0.069

Table 4. Panel data estimation results for the separate time period models. $t$-statistics are given in parentheses and are all robust to heteroskedasticity. Variables are defined in Section 2.6. Tests follow the convention in the literature. Period 1: 1972/19731983/1984 (the lagged dependent variable makes it necessary to dispense with 2 time points). Period 2: 1984/1985-1994/1995. Period 3: 1995/1996-2005/2006. Corr $\left(\mu_{i}, \mathrm{Xb}\right), \mathrm{R}_{2}$ within, rho and AR(1) test are obtained from the FE_tw model. Rho is the fraction of variance due to fixed effects $\mu_{i \cdot}{ }^{*} \mathrm{p}<0.1,{ }^{* *} \mathrm{p}<0.05,{ }^{* * *} \mathrm{p}<0.01$. All regressions include time dummies. Time dummy estimates are not displayed for space reasons. -: tests not relevant for this model

\begin{tabular}{|c|c|c|c|c|c|c|}
\hline \multirow[b]{2}{*}{ Variable/Test } & \multicolumn{3}{|c|}{ FE_tw_bc model } & \multicolumn{3}{|c|}{ _ SYS-GMM_gdp model } \\
\hline & Period 1 & Period 2 & Period 3 & Period 1 & Period 2 & Period 3 \\
\hline $\log$ nights $_{i t-1}$ & $\begin{array}{c}0.653^{* * *} \\
(24.83)\end{array}$ & $\begin{array}{c}0.592^{* * *} \\
(19.96)\end{array}$ & $\begin{array}{c}0.730^{* * *} \\
(26.73)\end{array}$ & $\begin{array}{c}0.595^{* * *} \\
(10.53)\end{array}$ & $\begin{array}{c}0.557^{* * *} \\
(5.73)\end{array}$ & $\begin{array}{c}0.698^{* * *} \\
(17.31)\end{array}$ \\
\hline $\log$ nights $_{\text {it-2 }}$ & $\begin{array}{c}0.084^{* * *} \\
(3.53)\end{array}$ & $\begin{array}{l}-0.003 \\
(-0.15)\end{array}$ & $\begin{array}{l}-0.031 \\
(-1.31)\end{array}$ & $\begin{array}{c}0.209^{* *} \\
(2.45)\end{array}$ & $\begin{array}{c}0.152^{* *} \\
(2.21)\end{array}$ & $\begin{array}{c}0.122^{* * *} \\
(3.37)\end{array}$ \\
\hline $\log s n o w_{\text {it }}$ & $\begin{array}{c}0.087^{*} \\
(1.9)\end{array}$ & $\begin{array}{c}0.058^{* *} \\
(2.37)\end{array}$ & $\begin{array}{c}0.060^{* * *} \\
(3.04)\end{array}$ & $\begin{array}{c}0.168^{* * *} \\
(5.22)\end{array}$ & $\begin{array}{c}0.092^{* * *} \\
(3.36)\end{array}$ & $\begin{array}{c}0.069^{* * *} \\
(2.96)\end{array}$ \\
\hline $\log g d p_{i t}$ & $\begin{array}{l}0.875 \\
(0.95)\end{array}$ & $\begin{array}{l}-0.005 \\
(-0.03)\end{array}$ & $\begin{array}{c}0.515 \\
(0.7)\end{array}$ & $\begin{array}{c}1.383^{* * *} \\
(3.32)\end{array}$ & $\begin{array}{l}0.071 \\
(0.29)\end{array}$ & $\begin{array}{l}0.188 \\
(1.29)\end{array}$ \\
\hline $\log b e d s_{i t}$ & $\begin{array}{c}0.100^{* *} \\
(2.24)\end{array}$ & $\begin{array}{c}0.255^{* * *} \\
(5.78)\end{array}$ & $\begin{array}{c}0.245^{* * *} \\
(7.06)\end{array}$ & $\begin{array}{c}0.232^{* *} \\
(2.39)\end{array}$ & $\begin{array}{c}0.360^{* *} \\
(2.1)\end{array}$ & $\begin{array}{c}0.219^{* * *} \\
(3.32)\end{array}$ \\
\hline $\log p p_{i t}$ & $\begin{array}{c}-0.050^{* * *} \\
(-2.80)\end{array}$ & $\begin{array}{l}0.002 \\
(0.04)\end{array}$ & $\begin{array}{l}-0.274 \\
(-1.28)\end{array}$ & $\begin{array}{l}-0.004 \\
(-0.10)\end{array}$ & $\begin{array}{l}-0.049 \\
(-1.18)\end{array}$ & $\begin{array}{l}-0.144 \\
(-1.17)\end{array}$ \\
\hline $\mathrm{R}^{2}$ within & 0.62 & 0.34 & 0.5 & - & - & - \\
\hline $\operatorname{Corr}\left(\mu_{i}, \mathrm{Xb}\right)$ & 0.95 & 0.96 & 0.94 & - & - & - \\
\hline Rho & 0.8 & 0.92 & 0.9 & - & - & - \\
\hline Pesaran AR(1) & 0.73 & $8.11^{* * *}$ & $1.78^{*}$ & - & - & - \\
\hline Diff AR(2) & - & - & - & 0.228 & 0.128 & 0.83 \\
\hline Sargan test & - & - & - & $<0.001$ & $<0.001$ & $<0.001$ \\
\hline Hansen test & - & - & - & 0.093 & 0.987 & 0.993 \\
\hline Diff_(GMM) & - & - & - & 0.899 & 1 & 1 \\
\hline Diff_(IV) & - & - & - & 0.358 & 1 & 1 \\
\hline No. of instruments & 0 & 0 & 0 & 136 & 244 & 249 \\
\hline No. of observations & 1850 & 2035 & 2035 & 1850 & 2035 & 2035 \\
\hline No. of groups & 185 & 185 & 185 & 185 & 185 & 185 \\
\hline Obs. per group & 10 & 11 & 11 & 10 & 11 & 11 \\
\hline
\end{tabular}


in Period 3. The difference is significant at the $10 \%$ level. This decline is also confirmed by the variable coefficient model, where snow coefficients are substantially lower for the last third of the time period. However, in the FE_tw_bc model, this declining trend was only weakly evident.

The results for the 2 extreme seasons (1989/1990 and 2006/2007) also correspond with the results of the panel data estimations and provide evidence that the impact of snow poor winters has dramatically decreased. Although meteorological conditions were similar in both seasons, the overall change in the growth rate of overnight stays was -8.1 percentage points in $1989 / 1990$ and only -2.7 percentage points in 2006/ 2007. Furthermore, the decrease was more pronounced in lower-lying areas and no noticeable changes were detected for higher-lying areas (above $1800 \mathrm{~m}$ ) or nonskiing areas in either of the two seasons.

\section{DISCUSSION}

In this section, we discuss 3 issues related to the presented results: the validity of the estimated elasticities, the decrease in the snow sensitivity and the interaction of climate with other factors.

The estimated snow elasticities of demand from time series regression and panel data models are well below one, meaning that, in the short-term, overnight stays are inelastic with respect to snow conditions. However, this does not necessarily hold for other demand indicators and time horizons, or for extreme seasons. For example, elasticities would probably be higher for direct ski lift tickets sales. Furthermore, in the long run elasticities are likely to be more pronounced, as tourists have time to adapt their behaviour to a long-term change in snow conditions. This means that, while impacts are rather limited in the short term, winner-loser patterns might well be observed in the long term as disadvantaged areas might exit the market (Elsasser \& Bürki 2002, Scott et al. 2006). Apart from that, demand response to snow-poor winter seasons might not be linear and elasticities might be higher for extreme seasons. The fact that the residuals in the ski area-specific ADL models are predominantly negative for the extreme winter season of 1989/1990 lends some support to this idea. However, 34 seasonal observations are not sufficient to check for nonlinearity - a more detailed framework would be required.

One key result of the present study is that snow sensitivity of overnight stays decreased substantially in recent years. This decrease might be attributed to the major increase in snowmaking and a subsequent decline in ski area dependency on natural snow cover.
Similar results have also been indicated for the northeastern US by Dawson et al. (2009). Their climate change analogue analysis shows that adaptations by ski businesses appear to have reduced the impacts of warm winters and that, for analogue years, reductions in season length were lower than those projected in supply-side studies. Of course, other factors such as quality improvements or an increased supply of tourist activities less sensitive to weather conditions might also be the reason for this observed trend. At any rate, these effects need to be evaluated more closely for individual areas, which would require additional information, e.g. data on the start of snowmaking in the respective areas.

Another important question is how the snow risk estimated in the present study is related to other risk factors for the tourism industry, such as economic conditions, terms of financing or socio-demographic changes. Economic and meteorological risks are basically uncorrelated, but they may add up at certain times. For example, the impacts of the world recession and economic crisis, such as a decline in sales or a tougher bank credit policy, will certainly challenge the tourism industry. This could increase the industry's exposure to additional risk factors, other than adverse weather conditions, putting the industry also more at risk from weather-related events.

\section{CONCLUSIONS}

The objective of the present study was to examine the impacts of snow conditions on tourism demand in Austrian ski areas on a local scale in the winter seasons 1973-2006. Using time series regression and panel data models, we found a positive relationship between overnight stays and snow conditions for the majority of areas, although higher-lying areas typically showed no dependency on their own snow conditions. However, for some of the higher-lying regions we found a negative dependency of overnight stays on average Austrian snow conditions.

Altogether, dependent on the estimation technique, a 1 SD change in snow conditions leads to a $0.6-1.9 \%$ change in overnight stays in ski areas, which corresponds to 300000 to 800000 overnight stays at current levels and, for extreme seasons, the impacts might be above this range. However, we suggest that, at current levels of adaptation, impacts should be in the lower portion of this range, as estimates from the more reliable approaches point in this direction and the observed decrease in sensitivity indicates that snow-poor winters will have less of an impact compared with previous decades.

A primary objective in climate impact research 
should be to further develop methodological tools to understand the impacts of climate variability on economic activities. As results from our econometric modelling show, one step in this direction is to apply dynamic time series regression methods or panel data methods, especially those considered to produce consistent and unbiased estimates. Overall, we think that results from these approaches are, in general, more robust than those found in supply-side studies or studies covering single years only, as they allow sensitivities to be compared between different regions and, in particular, observed over time. For the latter, our work shows that the results crucially depend on the period under research (presumably dependent on adaptation levels) and should, therefore, not be used automatically to predict impacts for future time periods without further analysis.

In summary, our results suggest that although season-to-season variability in weather has a substantial impact on the industry, in the long term other factors may prevail. However, before drawing far-reaching conclusions, a range of other questions need to be addressed and a closer look at interactions with economic processes is needed.

Take, for example, the case of snowmaking as a climate adaptation strategy. Its increased utilization reduces the exposure of ski areas towards natural snow conditions, but this positive effect could be offset in the longer term by a negative impact of price elasticity of demand. An evaluation of this counter effect requires better understanding of how price changes influence ski tourism as well as an analysis of the extent to which the costs of snowmaking investments have been passed directly on to consumers (or taxpayers, as some regions were subsidizing this kind of investment) rather than being covered by revenues from additional demand. Furthermore, when relative price changes become important factors explaining changes within tourism, a macroeconomic framework is needed, e.g. computed general equilibrium modelling. From an economic point of view, further research should go in this direction, particularly as recent work indicates that, although even at lower altitudes snow making might climatically still be possible under a $2{ }^{\circ} \mathrm{C}$ warming scenario, its intensified application will lead to significantly higher operation costs (Steiger \& Mayer 2008).

In addition, any change in tourism demand might have broader implications for the Austrian economy. Although this was not the focus of the present study, Prettenthaler et al. (2009) examined the impacts of a uniform $10 \%$ decrease in overnight stays in the winter season and showed that the overall macroeconomic effect in terms of GDP doubled the initial demand shock to tourism. Their results suggest that the most important negative macroeconomic effects are not to be borne by the tourism-intensive provinces such as Tyrol and Salzburg, but by Upper and Lower Austria, with their high share in the food industry and other sectors that deliver to the tourism sector. Thus, both lines of research, the macroeconomic approach just mentioned as well as the microeconomic approach we have presented in this paper, point to the importance of the regional scale in the further development of integrated economic assessment models of climate change impacts and adaptation.

Acknowledgements. Major parts of this research were generously supported by the Jubiläumsfonds of the ÖNB (Central Bank of the Republic of Austria). C.T. received a research grant from the URBI faculty of the University of Graz. The authors also thank B. Bednar-Friedl, A. Gobiet, H. Gurgul, J. Köberl, R. Mestel, R. Potzmann, S. Schiman, W. Schöner, K. Steininger, $\mathrm{M}$. Themessl and 3 anonymous reviewers for valuable contributions and helpful comments on this work.

\section{LITERATURE CITED}

Abegg B, Agrawala S, Crick F, de Montfalcon A (2007) Climate change impacts and adaptation in winter tourism. In: Agrawala S (ed) Climage change in the European Alps: Adapting winter tourism and natural hazards management. Organization for Economic Cooperation and Development, Paris, p 25-58

Agnew MD, Palutikof JP (2006) Impacts of short-term climate variability in the UK on demand for domestic and international tourism. Clim Res 31:109-120

Arellano M, Bond S (1991) Some tests of specification for panel data: Monte Carlo evidence and an application to employment equations. Rev Econ Stud 58:277-297

Arellano M, Bover O (1995) Another look at the instrumental variable estimation of error-component models. J Econom 68:29-51

Baltagi BH (2008) Econometric analysis of panel data, 4th edn. John Wiley, Chichester

Beck A, Hiebl J, Koch E, Potzmann R, Schöner W (2009) Institutionelle und regulatorische Fragestellungen der Bereitstellung von Wetterdaten. Economics of Weather and Climate Risks Working Paper Series 10/2009, Johanneum Research, Graz. Available at www.klimarisiko.at/node/42 bergfex (2009) Austrian ski areas. Available at www.bergfex.at/ BEV (Bundesamt für Eich- und Vermessungswesen) (2009) Austrian Map 3D Software. BEV, Vienna

Bigano A, Goria A, Hamilton JM, Tol RSJ (2005) The effect of climate change and extreme weather on tourism. In: Lanza A, Markandya A, Pigliaru F (eds) The economics of tourism and sustainable development. Edward Elgar, Cheltenham

Bigano A, Hamilton JM, Tol RSJ (2006) The impact of climate on holiday destination choice. Clim Change 76:389-406

Blundell R, Bond S (1998) Initial conditions and moment restrictions in dynamic panel data models. J Econom 87: 115-143

Breiling M, Charamza P (1999) The impact of global warming on winter tourism and skiing: a regionalised model for Austrian snow conditions. Reg Environ Change 1:4-14

$>$ Breusch TS (1978) Testing for autocorrelation in dynamic linear models. Aust Econ Pap 17:334-355 
Breusch TS, Pagan AR (1979) Simple test for heteroscedasticity and random coeffcient variation. Econometrica 47: 1287-1294

Bruno GSF (2005) Estimation and inference in dynamic unbalanced panel-data models with a small number of individuals. Stata J 5:473-500

- Dawson J, Scott D, McBoyle G (2009) Climate change analogue analysis of ski tourism in the northeastern USA. Clim Res 39:1-9

Elsasser H, Bürki R (2002) Climate change as a threat to tourism in the Alps. Clim Res 20:253-257

Fukushima T, Kureha M, Ozaki N, Fukimori Y, Harasawa H (2002) Influences of air temperature change on leisure industries: case study on ski activities. Mitig Adapt Strat Glob Change 7:173-189

Galloway RW (1988) The potential impact of climate changes on Australian ski fields. In: Pearmann GI (ed) Greenhouse: planning for climate change. CSIRO, Melbourne, p 428-437

Garín-Muñoz T, Montero-Martín LF (2007) Tourism in the Balearic Islands: a dynamic model for international demand using panel data. Tour Manag 28:1224-1235

Godfrey LG (1978) Testing against general autoregressive and moving average error models when the regressors include lagged dependent variables. Econometrica 46: 1293-1302

> Hamilton JM, Maddison DJ, Tol RSJ (2005) Climate change and international tourism: a simulation study. Glob Environ Change 15:253-266

Hamilton LC, Brown C, Keim BD (2007) Ski areas, weather and climate: Time series models for New England case studies. Int J Climatol 27:2113-2124

Harrison R, Kinnaird V, McBoyle G, Quinlan C, Wall G (1986) Recreation and climate change: a Canadian case study. Ontario Geogr 23:51-68

> Hennessy KJ, Whetton PH, Walsh K, Smith IN, Bathols JM, Hutchinson M, Sharples J (2008) Climate change effects on snow conditions in mainland Australia and adaptation at ski resorts through snowmaking. Clim Res 35:255-270

Jarque CM, Bera AK (1980) Efficient tests for normality, homoscedasticity and serial independence of regression residuals. Econ Lett 6:255-259

Joanneum Research (2008) Austrian ski resort database. JOANNEUM Research, Institute of Technology and Regional Policy, Graz

König U, Abegg B (1997) Impacts of climate change on winter tourism in the Swiss Alps. J Sustain Tourism 5:46-58

Laimer P, Smeral E (2006) Ein Tourismus-Satellitenkonto für Österreich: Methodik, Ergebnisse und Prognosen für die Jahre 2000 bis 2007. Statistics Austria and WIFO (Austrian Institute for Economic Research), Vienna

Lamothe \& Périard Consultants (1988) Implications of climate change for downhill skiing in Quebec. Climate Change Digest 88-03. Environment Canada, Ottawa

Lipski S, McBoyle G (1991) The impact of global warming on downhill skiing in Michigan. East Lakes Geogr 26:37-51

Editorial responsibility: Helmut Mayer, Freiburg, Germany
Lise W, Tol RSJ (2002) Impact of climate on tourist demand. Clim Change 55:429-449

Luzzi GF, Flückiger Y (2003) An econometric estimation of the demand for tourism: the case of Switzerland. Pac Econ Rev 8:289-303

> Maddison D (2001) In search of warmer climates? The impact of climate change on flows of British tourists. Clim Change 49:193-208

McBoyle G, Wall G (1992) Great Lakes skiing and climate change. In: Gill A, Hartman R (ed) Mountain resort development. Simon Fraser University, Centre for Tourism Policy and Research, Burnaby, p 71-81

> Nickell SJ (1981) Biases in dynamic models with fixed effects. Econometrica 49:1417-1426

OECD (2008) Consumer price index and gross domestic product. OECD, available at http://stats.oecd.org/

Prettenthaler F, Formayer H, Aumayer Ch, Haas P and others (2009) Global Change Impact on Tourism: Der sozioökonomische Einfluss des Klimawandels auf den Winter- und Sommertourismus in Österreich. Joanneum Research, Graz

Ramsey JB (1969) Tests for specification errors in classical linear least squares regression analysis. J R Stat Soc A 31: $350-371$

Roodman D (2009) How to do xtabond2: an introduction to 'Difference' and 'System' GMM in Stata. Stata J 9:86-136

Scott D, McBoyle G, Mills B (2003) Climate change and the skiing industry in southern Ontario (Canada): exploring the importance of snowmaking as a technical adaptation. Clim Res 23:171-181

Scott D, McBoyle G, Minogue A, Mills B (2006) Climate change and the sustainability of ski-based tourism in eastern North America: a reassessment. J Sustain Tourism 14:376-398

Scott D, Dawson J, Jones B (2008) Climate change vulnerability of the US Northeast winter recreation-tourism sector. Mitig Adapt Strategies Glob Change 13:577-596

Sequeira N, Nunes P (2008) Does country risk influence international tourism? A dynamic panel data analysis. Econ Rec 84:223-236

> Shih C, Nicholls S, Holecek DF (2009) Impact of weather on downhill ski lift ticket sales. J Travel Res 47:359-372

Song H, Witt SF, Li G (2009) The advanced econometrics of tourism demand. Routledge, New York

Statistics Austria (2008) Overnight stays in Austrian municipalities in the winter season 1973 to 2007. Statistics Austria, Vienna

Steiger R, Mayer M (2008) Snowmaking and climate change: future options for snow production in Tyrolean ski resorts. Mt Res Dev 28:292-298

Teich M, Lardelli C, Bebi P, Gallati D and others (2007) Klimawandel und Wintertourismus: Ökonomische und ökologische Auswirkungen von technischer Beschneiung. Eidg. Forschungsanstalt für Wald, Schnee und Landschaft, Birmensdorf

ZAMG (Central Institute for Meteorology and Geodynamics) (2009) $1 \times 1 \mathrm{~km}$ grid data for air temperature, precipitation and snow 1948-2006. ZAMG, Vienna

Submitted: April 22, 2010; Accepted: September 20, 2010 Proofs received from author(s): December 24, 2010 